February 2005 - NREL/CP-520-37345

\title{
Mechanisms of Growth of Nanocrystalline Silicon Deposited by Hot-Wire Chemical Vapor Deposition
}

H.R. Moutinho, C.-S. Jiang, Y. Xu, B. To, K.M. Jones, C.W. Teplin, and M.M. Al-Jassim

Prepared for the $31^{\text {st }}$ IEEE Photovoltaics Specialists Conference and Exhibition

Lake Buena Vista, Florida

January 3-7, 2005
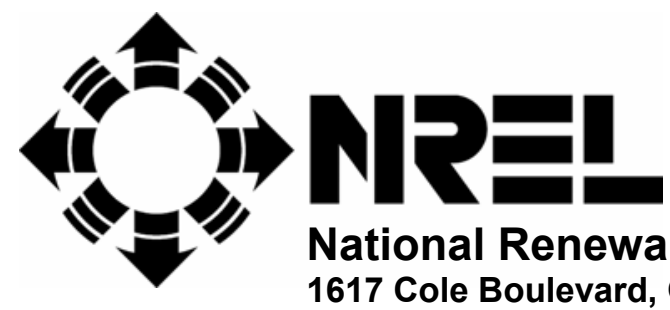

National Renewable Energy Laboratory 1617 Cole Boulevard, Golden, Colorado 80401-3393 303-275-3000 • www.nrel.gov

Operated for the U.S. Department of Energy

Office of Energy Efficiency and Renewable Energy

by Midwest Research Institute $\bullet$ Battelle

Contract No. DE-AC36-99-G010337 


\section{NOTICE}

The submitted manuscript has been offered by an employee of the Midwest Research Institute (MRI), a contractor of the US Government under Contract No. DE-AC36-99G010337. Accordingly, the US Government and MRI retain a nonexclusive royalty-free license to publish or reproduce the published form of this contribution, or allow others to do so, for US Government purposes.

This report was prepared as an account of work sponsored by an agency of the United States government. Neither the United States government nor any agency thereof, nor any of their employees, makes any warranty, express or implied, or assumes any legal liability or responsibility for the accuracy, completeness, or usefulness of any information, apparatus, product, or process disclosed, or represents that its use would not infringe privately owned rights. Reference herein to any specific commercial product, process, or service by trade name, trademark, manufacturer, or otherwise does not necessarily constitute or imply its endorsement, recommendation, or favoring by the United States government or any agency thereof. The views and opinions of authors expressed herein do not necessarily state or reflect those of the United States government or any agency thereof.

Available electronically at http://www.osti.gov/bridge

Available for a processing fee to U.S. Department of Energy and its contractors, in paper, from:

U.S. Department of Energy

Office of Scientific and Technical Information

P.O. Box 62

Oak Ridge, TN 37831-0062

phone: 865.576 .8401

fax: 865.576.5728

email: mailto:reports@adonis.osti.gov

Available for sale to the public, in paper, from:

U.S. Department of Commerce

National Technical Information Service

5285 Port Royal Road

Springfield, VA 22161

phone: 800.553 .6847

fax: 703.605.6900

email: orders@ntis.fedworld.gov

online ordering: http://www.ntis.gov/ordering.htm 


\title{
MECHANISMS OF GROWTH OF NANOCRYSTALLINE SILICON DEPOSITED BY HOT-WIRE CHEMICAL VAPOR DEPOSITION
}

\author{
H.R. Moutinho, C.-S. Jiang, Y. Xu, B. To, K.M. Jones, C.W. Teplin and M.M. Al-Jassim \\ National Renewable Energy Laboratory, Golden, CO 80401
}

\begin{abstract}
We have studied the growth of silicon thin films by hot-wire chemical vapor deposition under different conditions of filament temperature $\left(T_{f}\right)$ and hydrogen dilution ratio $(R)$. We found that these two parameters have a similar effect on the properties of the deposited films and show how they interact to control the growth dynamics. For relatively low values of $T_{f}$ and/or $R$, the films are amorphous. An increase in the value of these parameters results in the appearance of a new phase, characterized by heavily faulted (220)-oriented columnar grains; for even higher values, a randomly oriented nanocrystalline phase appears. In general, there is more than one phase present in the film, and the microstructure varies as we go from the bottom to the top of the film. Although $T_{f}$ and $R$ have similar effects on the physical properties, they affect the deposition rate in a different way.
\end{abstract}

\section{INTRODUCTION}

Nanocrystalline silicon (nc-Si) is cheaper to produce than crystalline silicon (c-Si), and thinner layers can be used to produce solar cells. In addition, it is a stable material and does not show degradation with light soaking [1], as observed with amorphous silicon (a-Si). Moreover, due to the differences in their bandgaps, it can be used in tandem solar cells with a-Si [2]. For this reason, the research on $\mathrm{nc}-\mathrm{Si}$ has been increasing over the last several years. A convenient method to grow nc-Si is by using hot-wire chemical vapor deposition (HWCVD) [3]. This technique is able to produce high-quality films and provides higher deposition rates than plasma-enhanced chemical vapor deposition (PECVD) because of the efficient decomposition of silane $\left(\mathrm{SiH}_{4}\right)$ into atomic species at the filament [4]. Nevertheless, at present, much work is still needed to correlate the several growth parameters with the quality of the produced films, and to create a unified model on the mechanisms of film growth.

This work complements previous research [5], in which we studied the effects of $\mathrm{R}$ on the structural properties of nc-Si films. Now we correlate the evolution of the microstructure, morphology, and crystalline properties of Si films with changes in the temperature of the filament used for film growth. We also study the interdependence of $T_{f}$ with $R$, and explain how the film growth, and consequent film structure, is determined by these parameters.

\section{EXPERIMENTAL PROCEDURE}

The films were deposited using a double W filament, with the following values for the current in each filament: $12 \mathrm{~A}\left(\approx 1780^{\circ} \mathrm{C}\right), 13 \mathrm{~A}\left(\approx 1880^{\circ} \mathrm{C}\right), 14 \mathrm{~A}\left(\approx 1980^{\circ} \mathrm{C}\right)$ and 15 A $\left(\approx 2080^{\circ} \mathrm{C}\right)$. For currents below $12 \mathrm{~A}$ there was no deposition of film on the substrate, probably a result of the formation of silicides on the filament surface at these relatively low temperatures, which prevented the decomposition of silane [6]. We also produced films with the following values of $\mathrm{R}: 14,25$, and 50 . These values are the ratio between the $\mathrm{H}_{2}$ and $\mathrm{SiH}_{4}$ flow rates. In our experiment, we keep the $\mathrm{H}_{2}$ flow rate at $252 \mathrm{sccm}$, and vary the flow of silane. The implication for this procedure is that, as we vary the silane flow rate, the relative number of silicon and hydrogen atoms produced at the filament changes. We used three kinds of substrates: glass, c-Si, and $\mathrm{SnO}_{2}$, for comparison purposes, and because certain analyses require a specific type of substrate.

The crystalline structure of the films was investigated with X-ray diffraction (XRD), in a Scintag X1 system, using the Bragg-Brentano configuration. The relative amounts of amorphous and crystalline phases were investigated using Raman spectroscopy, with a single-grating Spex $270 \mathrm{M}$ spectrometer, using both 532 (green) and $633 \mathrm{~nm}$ (red) lasers to obtain information from different depths of the material. We studied the microstructure of the films with transmission electron microscopy (TEM) in a Philips CM30 TEM. To study the surface topography, we used atomic force microscopy (AFM), with Si tips, in a Digital Instruments Dimension 3100 scanning probe microscope (SPM). Finally, to investigate the electrical properties of the films, we used conductive-AFM (C-AFM), also in a Dimension 3100 SPM, using conductive diamond tips.

\section{RESULTS}

We did not notice any major differences in the results of AFM and XRD analyses performed in films deposited on different substrates but with the same deposition parameters. For the other analyses, we used films deposited on specific substrates: Si substrate, for Raman and TEM, and conductive $\mathrm{SnO}_{2}$, for C-AFM.

\section{Deposition Rate}

High deposition rate is a feature that distinguishes HWCVD from other techniques, such as PECVD, in the growth of $\mathrm{Si}$ thin films. The reason for this is the efficient dissociation of the silane and hydrogen molecules on the 
heated filament. For instance, it has been reported that, for filament temperatures above $1500^{\circ} \mathrm{C}$, every silane molecule that reacts with the filament is completely dissociated $[4,7]$. Filament temperature and dilution ratio are probably the two most important parameters controlling the deposition rate. The influence of these parameters is shown in Fig. 1. It is clear that their effect on deposition rate is opposite, which is explained by the fact that an increase in $T_{f}$ increases the amount of atomic silicon available for film growth, consequently increasing the deposition rate. On the contrary, an increase in the dilution ratio, obtained by decreasing the flow rate of silane, results in fewer Si atoms and, consequently, in a decrease of the deposition rate. As we will see below, an independent increase in both $T_{f}$ and $R$ increases the amount of the nanocrystalline phase in the film. This will impose a compromise on the best value for $\mathrm{R}$, but not on the value for $T_{f}$. An upper limit on the value of $T_{f}$ may come from the fact that the nc-Si films grown at higher temperatures (above $1930^{\circ} \mathrm{C}$ ) have been observed to have a porous microstructure, and minimal photoresponse [8].

\section{X-Ray Diffraction}

The diffraction peaks for all the samples corresponded to the cubic structure of silicon (JCPDS card number 27-1402). The only exception was a peak located at $26.9^{\circ}$, observed for most samples. We have observed this peak in the XRD data presented by other authors [6,9] and, to our knowledge, it has not been positively identified yet. Because the results were the same for films deposited in different substrates, including the relative peak intensity, for simplicity we present the results for films deposited on glass, because this substrate does not produce peaks in the diffraction pattern.

The XRD analysis showed that there is a close relationship between filament temperature and dilution ratio. Furthermore, an increase in each of these parameters separately has the same effect on the films.

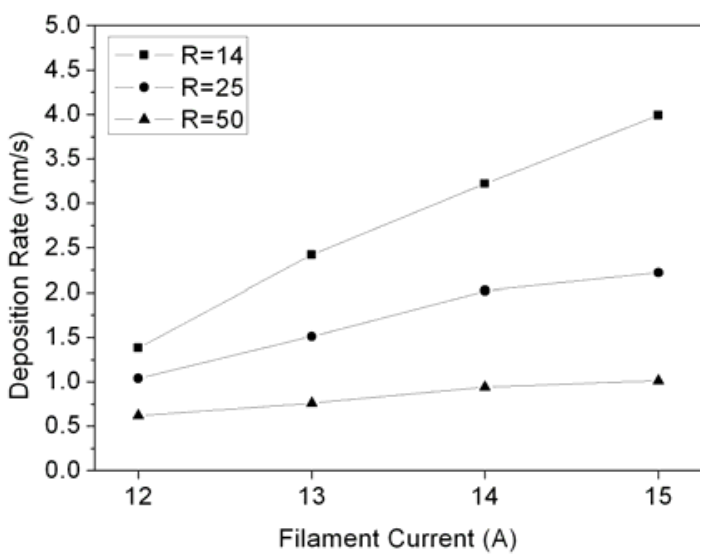

Fig. 1. Deposition rate as a function of filament current (directly related to $\mathrm{T}_{\mathrm{f}}$ ) and dilution ratio.
In Fig. $2 a$, we show the evolution of the crystallinity with $T_{f}$ for a value of $R$ equal to 14. A low value of $T_{f}$ results in mostly amorphous films. As $T_{f}$ increases, a new (220)oriented phase appears. For higher values of $T_{f}, a$ randomly oriented phase appears. This phase has been shown to be nanocrystalline [5]. The relative amount of each phase also varies as $T_{f}$ is increased, with films deposited with higher filament temperatures being more nanocrystalline. For the conditions used in this work, most films were composed of more than one phase. The evolution of this process is also a function of $R$, as shown in Fig. 2. It is clear that the effect of varying $T_{f}$ is strongly affected by the value of $R$. Similarly, the effect of varying $R$ depends on the value of $T_{f}$, as can be observed if we compare curves from Figs. $2 a$ and $2 b$ with the same value of $T_{f}$. Because of this interrelationship, there is not a unique value of $R$ or $T_{f}$ separately that will guarantee that the film has a given crystalline structure.

\section{Raman Spectroscopy}

In Fig. $3 a$ and $3 b$ we show the Raman spectra of the same samples analyzed by XRD (Fig. 2), using a $633 \mathrm{~nm}$ laser beam. Raman provides a measure of the relative

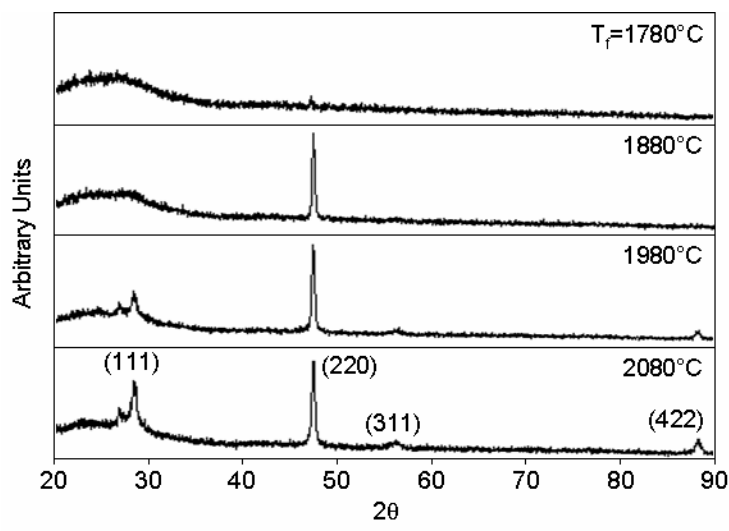

(a)

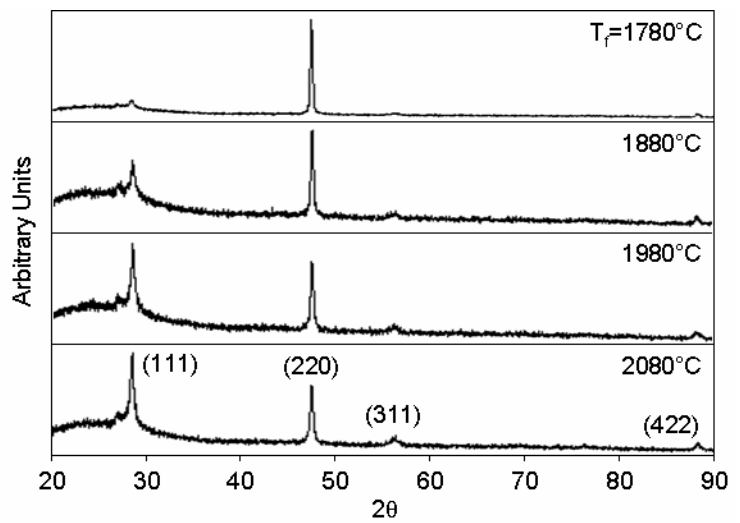

(b)

Fig. 2. X-ray diffraction patterns from silicon thin films deposited on glass and grown with different filament temperatures. (a) $R=14$; (b) $R=25$. 


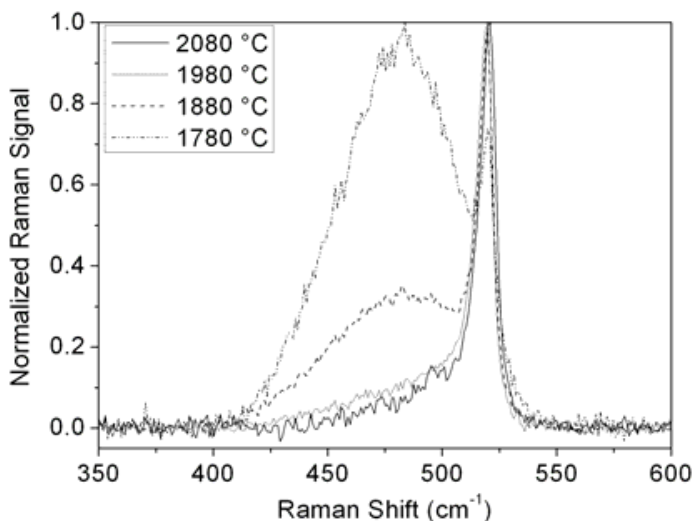

(a)

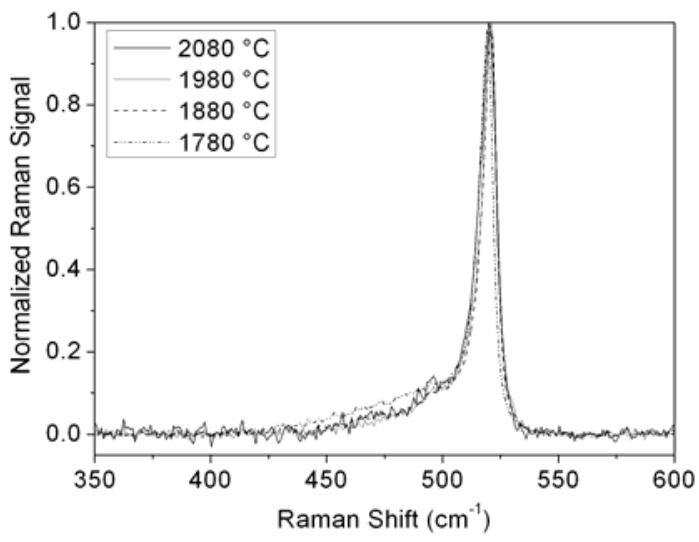

(b)

Fig. 3. Raman spectra of silicon thin films grown at different filament temperatures. (a) $R=14$; (b) $R=25$.

amounts of crystalline and amorphous phases in the films, but cannot distinguish between the different crystalline phases. Crystalline material shows a sharp Raman peak at $520 \mathrm{~cm}^{-1}$, while amorphous material has a broader peak at lower wavenumber. The Raman data is consistent with the XRD results in that both increasing $T_{f}$ and increasing $R$ result in more crystalline films (Fig. 3). In Fig. 3b, we see that $R$ is large enough to produce mostly crystalline films, even at the lowest filament temperature. Raman spectra acquired with a $532 \mathrm{~nm}$ laser beam show a similar trend as the data in Fig. 3, but the amorphous peaks are generally smaller in comparison to the crystalline peaks. Because the optical penetration depth in Si at $532 \mathrm{~nm}$ is smaller than at $633 \mathrm{~nm}$, this suggests that the films are more crystalline near to the surface and more amorphous at the film/substrate interface.

\section{Transmission Electron Microscopy}

Four phases were identified in the TEM analysis: epitaxial $\mathrm{Si}$, amorphous and nanocrystalline phases, and (220)-oriented columnar grains. The relative amounts of these phases depend on the values of $T_{f}$ and $R$, and more than one phase is present in most films. Because of sample preparation issues, we could not precisely follow the evolution of film microstructure with $T_{f}$ and $R$. Nevertheless, the TEM results fit the Raman and XRD results. For $T_{f}$ equal to $1880^{\circ} \mathrm{C}$ and $\mathrm{R}$ equal to 14 , the film is composed of columnar grains, forming close to the interface with the substrate and growing all the way to the film surface, surrounded by an amorphous phase. These grains are heavily faulted, and electron diffraction showed that they are the (220) grains observed in XRD. For higher values of $T_{f}$ and $R$, the amount of the amorphous phase decreases, and the films are mostly formed by columnar grains surrounded by nc-Si. In the conditions used in this work, even for the higher values of $T_{f}$ and $R$, the columnar grains are still present. Nevertheless, in films grown previously, with $R$ equal to 100 and $T_{f}$ equal to $1880^{\circ} \mathrm{C}$, we produced films with some epitaxial growth and nanocrystalline phase only [5]. Figure 4 shows the microstructure of a film with $\mathrm{R}$ equal to 14 and $\mathrm{T}_{\mathrm{f}}$ equal to $2080^{\circ} \mathrm{C}$. Few columnar grains are visible. Nevertheless, for these grains to be visible, the sample has to be positioned on the right diffraction condition; so not all the columnar grains are visible at once. An electron diffraction pattern of this film is seen in the inset of Fig. 4, where the presence of both phases is clear. The rings are characteristics of an area with small randomly oriented grains, whereas the spots are typical of the oriented material.

\section{Atomic Force Microscopy}

Due to the nature of the Si surface, even the amorphous material looks to be composed by small grains. The parameter that differentiates the amorphous phase from the nanocrystalline phase is the roughness, which is about ten times higher for the nanocrystalline phase. Also, the (220) columnar grains seemed to be formed by small grains at the surface, which makes it difficult to isolate the nanocrystalline and the (220) phases at the surface unambiguously. For $R$ equal to 14 and $T_{f}$ equal to $1780^{\circ} \mathrm{C}$, the surface of the film is formed by elongated grains (the columnar grains observed in TEM), surrounded by a relatively smooth amorphous phase. As we increased $\mathrm{R}$ or $\mathrm{T}_{\mathrm{f}}$, the amorphous phase disappeared (in the Raman analysis, we observed that the material is more crystalline at the surface), the number of elongated grains increased, and a nanocrystalline structure appeared (grain size varying mostly from 30 to $80 \mathrm{~nm}$ ). For further increase in $R$, the number of elongated grains decreased and the amount of the nanocrystalline phase increased. To a lesser extent, the same effect seemed to be present for further variation in $T_{f}$.

\section{Conductive-Atomic Force Microscopy}

The analysis confirmed that the crystalline phase is significantly more conductive than the amorphous phase. Nevertheless, it was not possible to make a correlation between the current and the amounts of the nanocrystalline and the (220)-oriented phases. The technique proved to be especially useful for detecting the (220) columnar grains from the amorphous phase. On the AFM images, it is difficult to distinguish the (220) grains 


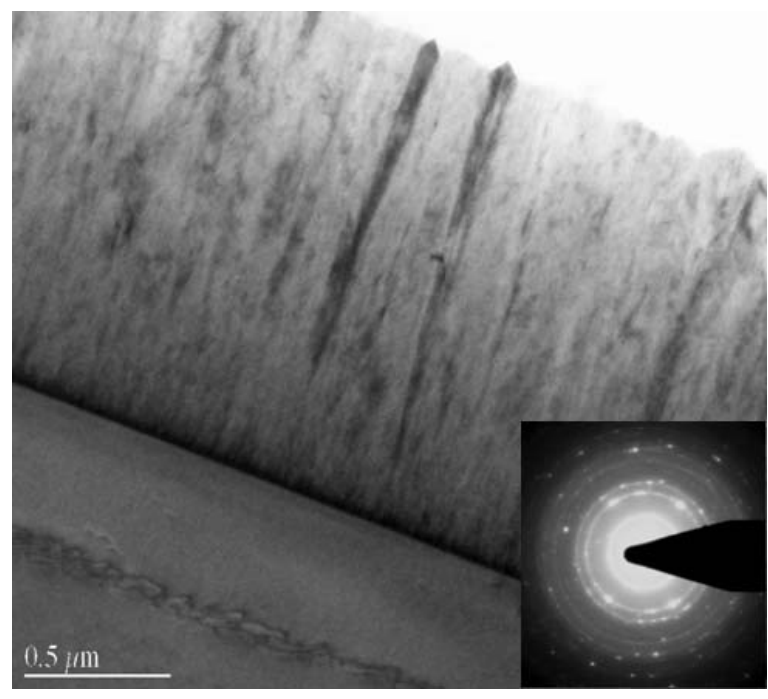

Fig. 4. Transmission electron microscopy of a Si film grown with $R=14$ and $T_{f}=2080^{\circ} \mathrm{C}$. The inset shows an electron diffraction pattern of the same film.

from grain-like structures that we believe to be amorphous material. However, on the C-AFM image, the (220)oriented grains produce a higher current and are easily distinguishable. Due to lack of space, these results will be presented in more detail in a future publication.

\section{DISCUSSION}

By increasing the hydrogen dilution ratio in the chamber, we increase the relative amount between atomic hydrogen and silicon. This results in more etching of weak bonds during film growth, resulting in more crystalline films. Similarly, an increase in the filament temperature also produces more atomic hydrogen, increasing the etching process. For this reason, a variation of $T_{f}$ and $R$ produces similar results, as we have observed. Our results also demonstrate that the growth process of nanocrystalline $\mathrm{Si}$ is very complex, and it is very difficult to produce the material with a single phase, unless we use high values of $T_{f}$ and/or $R$. The growth of the columnar grains for relatively low concentration of $\mathrm{H}$ indicates that this phase grows faster than the nanocrystalline phase, but the bonds may be relatively weak. We believe that, for higher concentrations of atomic hydrogen, weak bonds in the (220) phase are etched way, resulting in the preferential growth of the nanocrystalline phase.

\section{CONCLUSIONS}

We have shown that the growth of nanocrystalline silicon films is complex, and, in general, results in a material with more than one phase. The filament temperature and the hydrogen dilution ratio have a similar effect on the properties of the films, and there is interdependence between these two parameters, which is related to the relative amounts of silicon and hydrogen atoms available during film growth. For lower values of $T_{f}$ and $\mathrm{R}$, the film is mostly amorphous, with the development of a (220)-oriented columnar grain structure, and, subsequently, a nanocrystalline structure, as the values of these parameters are increased. On the contrary, although an increase in $\mathrm{R}$ decreases the deposition rate, an increase in $T_{f}$ promotes a faster growth of the films.

\section{ACKNOWLEDGES}

We would like to thank Brent Nelson for valuable discussions on the growth mechanisms of nanocrystalline silicon. This work was supported by the U.S. Department of Energy under Contract number DE-AC36-99G010337.

\section{REFERENCES}

[1] J.P. Kleider, C. Longeaud, R. Bruggemann, and F. Houze, "Electronic and Topographic Properties of Amorphous and Microcrystalline Silicon Thin Films," Thin Solid Films 383, 2001, pp. 57-60.

[2] Y. Hamakawa and H. Takakura, "Key Issues for the Efficiency Improvement of Silicon Basis Stacked Solar Cells," Proc. Twenty-Eighth IEEE PVSC, 2000, pp. 766771.

[3] M. Konagai, T. Tsushima, Y. Ide, K, Asakusa, T. Jujisaki, M.K. Kim, Y. Wakita, and A. Yamada, "High Rate Deposition of Silicon Thin Films by Hot Wire Cell Method for Solar Cell Applications," Proc. Twenty-Eighth IEEE PVSC, 2000, pp. 788-791.

[4] R.E.I. Schropp, "Present Status of Hot Wire Chemical Vapor Deposition Technology," Mat. Res. Soc. Symp. Proc. 762, 2003, pp. A13.1.1-A13.1.12.

[5] H.R. Moutinho, C.-S. Jiang, J. Perkins, Y. Xu, B.P. Nelson, K.M. Jones, M.J. Romero, and M.M. Al-Jassim, "Effects of Dilution Ratio and Seed Layer on the Crystallinity of Microcrystalline Silicon Thin Films Deposited by Hot-Wire Chemical Vapor Deposition," Thin Solid Films 430, 2003, pp. 135-140.

[6] C.H.M. van der Werf, P.A.T.T. van Veenendaal, M.K van Veen, A.J. Hardeman, M.Y.S. Rushche, J.K. Rath, and R.E.I. Schropp, "The Influence of the Filament Temperature on the Sturcture of Hot-Wire Deposited Silicon," Thin Sold Films 430, 2003, pp. 46-49.

[7] J. Doyle, R. Robertson, G.H. Lin, M.Z. He, and A Gallagher, "Production of High-Quality Amorphous Silicon Films by Evaporative Silane Surface Decomposition," J. Appl. Phys. 64, 1988, pp. 3215-3223.

[8] R.E.I. Schropp, Y. Xu, E. Iwaniczko, G.A. Zaharias, and A. Mahan, "Microcrystalline Silicon for Solar Cells at High Deposition Rates by Hot Wire CVD," Mat. Res. Soc. Symp. Proc. 715, 2002, pp. A26.3.1-A26.3.6.

[9] J.K. Rath, A.J. Hardeman, C.H.M. van der Werf, P.A.T.T. van Veenendaal, M.Y.S. Rusche, and R.E.I. Schropp, "Deposition of HWCVD Poly-Si Films at a High Growth Rate," Thin Sold Films 430, 2003, pp. 67-72. 


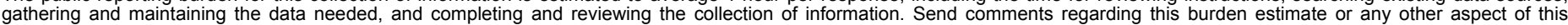

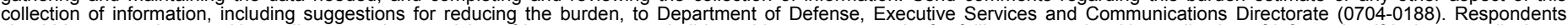

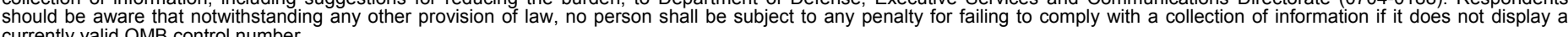

PLEASE DO NOT RETURN YOUR FORM TO THE ABOVE ORGANIZATION.

\section{REPORT DATE (DD-MM-YYYY) \\ February 2005}

4. TITLE AND SUBTITLE

Mechanisms of Growth of Nanocrystalline Silicon Deposited by Hot-

Wire Chemical Vapor Deposition
3. DATES COVERED (From - To)

3-7 January 2005

5a. CONTRACT NUMBER

DE-AC36-99-GO10337

5b. GRANT NUMBER

5c. PROGRAM ELEMENT NUMBER

5d. PROJECT NUMBER

NREL/CP-520-37345

5e. TASK NUMBER

PVA53002

5f. WORK UNIT NUMBER
7. PERFORMING ORGANIZATION NAME(S) AND ADDRESS(ES)

National Renewable Energy Laboratory

1617 Cole Blvd.

Golden, CO 80401-3393
8. PERFORMING ORGANIZATION REPORT NUMBER

NREL/CP-520-37345

9. SPONSORING/MONITORING AGENCY NAME(S) AND ADDRESS(ES)

10. SPONSOR/MONITOR'S ACRONYM(S) NREL

11. SPONSORING/MONITORING AGENCY REPORT NUMBER

12. DISTRIBUTION AVAILABILITY STATEMENT

National Technical Information Service

U.S. Department of Commerce

5285 Port Royal Road

Springfield, VA 22161

13. SUPPLEMENTARY NOTES

14. ABSTRACT (Maximum 200 Words)

We have studied the growth of silicon thin films by hot-wire chemical vapor deposition under different conditions of filament temperature $\left(T_{f}\right)$ and hydrogen dilution ratio $(R)$. We found that these two parameters have a similar effect on the properties of the deposited films and show how they interact to control the growth dynamics. For relatively low values of $\mathrm{T}_{f}$ and/or $\mathrm{R}$, the films are amorphous. An increase in the value of these parameters results in the appearance of a new phase, characterized by heavily faulted (220)-oriented columnar grains; for even higher values, a randomly oriented nanocrystalline phase appears. In general, there is more than one phase present in the film, and the microstructure varies as we go from the bottom to the top of the film. Although $\mathrm{T}_{\mathrm{f}}$ and $\mathrm{R}$ have similar effects on the physical properties, they affect the deposition rate in a different way.

15. SUBJECT TERMS

PV; nanocrystalline silicon; thin films; hot-wire chemical vapor deposition (HWCVD); filament temperature ( $\left.T_{f}\right)$; hydrogen dilution ratio $(\mathrm{R})$;

\begin{tabular}{l|l|l|}
\hline \multicolumn{1}{|c|}{ 16. SECURITY CLASSIFICATION OF: } \\
\hline $\begin{array}{l}\text { a. REPORT } \\
\text { Unclassified }\end{array}$ & $\begin{array}{c}\text { b. ABSTRACT } \\
\text { Unclassified }\end{array}$ & $\begin{array}{l}\text { c. THIS PAGE } \\
\text { Unclassified }\end{array}$ \\
\hline
\end{tabular}

\begin{tabular}{|l|l|}
$\begin{array}{l}\text { 17. } \\
\text { LIMITATION } \\
\text { OF ABSTRACT } \\
\text { UL }\end{array}$ & $\begin{array}{l}\text { 18. } \\
\text { NUMBER } \\
\text { OF PAGES }\end{array}$ \\
&
\end{tabular}

19a. NAME OF RESPONSIBLE PERSON

19b. TELEPHONE NUMBER (Include area code) 